Article

\title{
Who Is a Stream? Epistemic Communities, Instrument Constituencies and Advocacy Coalitions in Public Policy-Making
}

\author{
Ishani Mukherjee ${ }^{1}$ and Michael Howlett ${ }^{1,2, *}$ \\ ${ }^{1}$ Lee Kuan Yew School of Public Policy, National University of Singapore, 259772 Singapore, Singapore; \\ E-Mail: ishani@nus.edu.sg \\ ${ }^{2}$ Department of Political Science, Simon Fraser University, Burnaby, V5A1S6, Canada; E-Mail: howlett@sfu.ca \\ * Corresponding author
}

Submitted: 11 April 2015 | In Revised Form: 3 August 2015 | Accepted: 7 August 2015 |

Published: 26 August 2015

\begin{abstract}
John Kingdon's Multiple Streams Framework (MSF) was articulated in order to better understand how issues enter ed onto policy agendas, using the concept of policy actors interacting over the course of sequences of events in what he referred to as the "problem", "policy" and "politics" "streams". However, it is not a priori certain who the agents are in this process and how they interact with each other. As was common at the time, in his study Kingdon used an undifferentiated concept of a "policy subsystem" to group together and capture the activities of various policy actors involved in this process. However, this article argues that the policy world Kingdon envisioned can be better visualized as one composed of distinct subsets of actors who engage in one specific type of interaction involved in the definition of policy problems: either the articulation of problems, the development of solutions, or their enactment. Rather than involve all subsystem actors, this article argues that three separate sets of actors are involved in these tasks: epistemic communities are engaged in discourses about policy problems; instrument constituencies define policy alternatives and instruments; and advocacy coalitions compete to have their choice of policy alternatives adopted. Using this lens, the article focuses on actor interactions involved both in the agenda-setting activities Kingdon examined as well as in the policy formulation activities following the agenda setting stage upon which Kingdon originally worked. This activity involves the definition of policy goals (both broad and specific), the creation of the means and mechanisms to realize these goals, and the set of bureaucratic, partisan, electoral and other political struggles involved in their acceptance and transformation into action. Like agenda-setting, these activities can best be modeled using a differentiated subsystem approach.
\end{abstract}

\section{Keywords}

advocacy coalition framework; epistemic communities; multiple streams framework; policy formulation; policy subsystems

\section{Issue}

This article is part of a regular issue of Politics and Governance, edited by Professor Andrej J. Zwitter (University of Groningen, The Netherlands) and Professor Amelia Hadfield (Canterbury Christ Church University, UK).

(C) 2015 by the authors; licensee Cogitatio (Lisbon, Portugal). This article is licensed under a Creative Commons Attribution 4.0 International License (CC BY).

\section{Introduction: Agency and the Multiple Streams Model}

Since its first articulation in the early 1980s, John Kingdon's Multiple Streams Framework (MSF) has been one of the main models of the policy process utilized in contemporary policy research (Kingdon, 1984, 2011). As is well known, in his study of the agenda-setting stage of the policy process, Kingdon envisioned three independently flowing streams of events - the political, policy and problem "streams"-brought together by focusing events and fortuitous windows of opportunity 
to elevate policy items from the unofficial or public agenda onto the government one. Highlighting the contingency of policy decision making efforts, Kingdon drew on the so-called "garbage can" theory of organizational choice in exploring how some issues come to light in ambiguous policy contexts dependent on the actions of unpredictable sets of actors (Cohen, March, \& Olsen, 1972; March \& Olsen, 1979).

Specifically, Kingdon was concerned with "what makes people in and around government attend, at any given time, to some subject and not to others?" (Kingdon, 2011, p. 1). But, who is the agent here? That is, who represents and actualizes a "stream" of events or a response to it? While Kingdon, using a specific case of US policymaking, emphasized the role of certain kinds of actors such as policy entrepreneurs in catalyzing the merging of streams, in general it is not clear in this model who are the actors that give each stream, to paraphrase Kingdon's words, "a life of its own".

This is not to say Kingdon's work lacks agency, but rather that in his work the principle player, as was commonly held by many policy theorists in the early 1980s and 1990s (McCool, 1998; Sabatier, 1991), was the "subsystem" or policy "community". This community is defined as a relatively undifferentiated and cohesive set of actors bound together by a common concern with a policy subject area, distinguishable in this sense from the "policy universe" of all possible policy actors active at a point in time (Howlett \& Cashore, 2009; Howlett, Ramesh, \& Perl, 2009; Kingdon, 2011). Within this subsystem Kingdon highlighted the role played by some specialized actors - "brokers" or "policy entrepreneurs" - who were able to mobilize support for particular issue definitions and promote the salience of particular issues among other subsystem members.

This vision of policy actors sufficed for Kingdon's analysis of agenda-setting activities which was concerned with understanding how a policy "condition" moved from the "policy universe" or undifferentiated public, societal, locus of policy attention, to become a "problem" occupying a more focused group of actors; one which had the knowledge, power and resources required to articulate the nature or "frame" of a problem and some possible solutions for it; allowing it to then move forward for consideration by government.

While Kingdon thus systematically analyzed the structural mechanics of how such subsystems operated to reduce the number of alternative possible agendaitems to the much smaller number which receive government attention, and to prioritize problems within that smaller group, his concept of "streams" or sequences of events involved in this process fit uneasily with these subsystem notions. That is, while his concept of brokers or entrepreneurs helped understand how problem definitions and solutions were combined, he was not clear about precisely who was involved in defining and selecting one or more solution over any other or in defining or framing a problem in a particular fashion rather than some other.

This lack of a detailed conception of agency in Kingdon's original model has left a significant gap in existing work based on his framework. This has made it difficult to understand policy-making dynamics from this perspective, as saying streams of events "flow and interact" with each other is not very revealing of the mechanisms at work in this process. Without a clearer notion of agency it is difficult to see how essential phenomena such as "streams" intersecting or agendaitems "moving forward" actually occur in practice (Hood, 2010; Howlett, 2012). ${ }^{1}$

That is, merely saying that multiple streams and multiple phases of policy-making exist, as scholars basing their work on Kingdon's (1984) lead have often done, begs the question of how the processes identified by Kingdon are actually carried out by policy agents. If the multiple streams framework is to say anything meaningful about policy-making it has to address head-on questions about the nature of the streams identified by Kingdon, including how they come in to existence and how they operate and evolve.

Two major challenges in particular must be overcome if the MSF framework is to provide a useful model of the policy-making process:

1) How to operationalize or agentify the various streams of events and activities involved in policy-making in order to be able to analytically distinguish them from each other and analyse their interactions during different phases of the policy process; and

2) How to analyse periods of separation and coming together of one or more of the streams before, after and during different phases of policy making activity in terms of these actor relationships.

In this article we endeavor to address this gap and enhance the continuing contribution the MSF has made to modern public policy thinking by exploring how the

\footnotetext{
${ }^{1}$ This is especially significant for those desiring to take the multiple streams framework forward to cover policymaking beyond its initial stages. As Howlett, McConnell and Perl (2015) have shown, many of these authors have simply carried forward the idea of a three-stream confluence remaining in place following agenda-setting in order to cover off activities occurring at subsequent stages of the policy process (Teisman, 2000). Others, however, have suggested that after an item enters the formal agenda, at least some of the streams split off once again to resume their parallel courses (Teisman, 2000; Zahariadis, 2007). And yet others have suggested that additional streams emerge and can become apparent through and beyond agenda setting, such as those involved in operational administrative processes once a problem has been established (Howlett et al., 2015; Zahariadis, 2007).
} 
streams metaphor can be better visualized to incorporate more precise notions of agency. The article examines Kingdon's own thoughts about actors and criticisms of those notions which suggest the existence of several distinct kinds of entrepreneurs. It uses this insight to establish a framework for further empirical testing which advances an agency-based distinction among each of the three main streams identified in Kingdon's work (Howlett et al., 2015).

Studying policy-making through this lens promises to bear fruit in providing a much better understanding of how each stream operates and how subsets of actors within the policy subsystem interact or disconnect from each other during the course of the policymaking process, affecting both the timing, content and impact of policies. Viewing a subsystem as composed of distinct subsets of actors engaged in specific policy, problem and political tasks in this way, we argue, provides a superior model of policy-making to an undifferentiated subsystem conception.

Such a model acknowledges that the interactions among these groups of actors drives policy-making forward. It also helps drive policy theory forward by clarifying "who is a stream" and helping to adapt the MSF model to both agenda-setting and activities beyond this early stage of policy-making (Howlett et al., 2015).

\section{Policy Subsystems and Entrepreneurs: The Concept of Agency in Kingdon's Work}

Greater specification of agent activities is required both to better understand agenda-setting behavior and in order to understand how Kingdon's model can best be applied to activities in policy-making beyond the agenda-setting activities he examined. Many attempts at extending the MSF model beyond agenda-setting have been less than successful in matching or describing policy empirics involved in policy formulation and beyond because they have inherited from Kingdon only very weak depictions of what is a stream and, more to the point, of whom it is composed (Howlett et al., 2015).

In what follows below, two key aspects of Kingdon's work with respect to his treatment of agency are examined. The first concerns his use of the concept of a policy subsystem as a generic catch-all category for policy actors, while the second concerns his use of the concept of "policy entrepreneurs" as agents providing the linkage across streams needed for agenda-setting issue entrance to occur. As shall be shown, both of these conceptions are related and both are problematic in applying the model in practice.

\subsection{Policy Subsystems and Policy Entrepreneurs}

Kingdon's own work uses the notion of a "subsystem" as a key grouping of policy actors in making its arguments and claims about policy processes and outcomes. As
McCool (1998) pointed out, the subsystem family of concepts was developed beginning in the late 1950s in order to help better understand the role of interests and discourses in the policy process by allowing for complex formal and informal interactions to occur between both state and non-state actors. The scholarship on such policy actors in the 1970s to 1990s was legion and included a wide variety of sometimes competing concepts such as "iron triangles", "sub-governments", "cozy triangles", "power triads", "policy networks", "issue communities", "issue networks", "advocacy coalitions", and "policy communities", among others, all alluding to the tendency of policy actors to form substantive issue alliances that cross institutional boundaries and include both governmental and nongovernmental actors (Arts, Leroy, \& van Tatenhove, 2006; Freeman, 1997; McCool, 1998).

The relationship between ideas, interests, institutions and actors found in subsystems was highlighted in subsystem theory. This was something previous policy theory had largely ignored since its focus had typically been upon formal institutional procedures and relationships between governmental and non-governmental agents active in policy-making such as interest groups and lobbyists (Howlett et al., 2009; McCool, 1998). The more subtle subsystem concept which merged actors, ideas and institutions together allowed students of the policy sciences to distinguish more precisely who were the key actors in a policy process, what unites them, how they engage each other and what effect their dealings had on policy outcomes than was possible using a more formal institutional lens (Howlett et al., 2009).

This view allows the development of a uniting framework of analysis that can, firstly, establish patterns that perpetuate action from one stage of the policy process to another and, secondly, analytically deconstruct the "black box" of each stage, introducing a more nuanced and dynamic view of policymaking than was typically found in older, more institutional analyses (Howlett et al., 2009). Thus as Kingdon rightly noted, in general the subsystem is an appropriate unit of analysis for distinguishing the actors involved in the politics, process and problem aspects of policy-making activities such as agenda-setting in which informal interactions were just as important as formal ones in terms of explaining the timing and content of issue attention.

But it is not clear in using a subsystem conception how it is that the "streams" of political, policy and problem events Kingdon highlighted were kept separate or how they can be brought together only periodically rather than affect subsystem members equally and at all times. While the former point was not addressed in his work, it is to deal with the latter that Kingdon introduced a second category of actors, the "policy entrepreneur", key actors whose role it was to link problem and solutions and political circumstances, allowing an 
issue to enter onto a government agenda and largely controlling its timing.

\subsection{The Key Role of Policy Entrepreneurs}

Much attention in his own analysis was given by Kingdon to the singular role played by such entrepreneurs in moving agenda items forward into the formal policy process. In line with the "garbage can" theory of policymaking upon which he drew for inspiration (Cohen et al., 1972), Kingdon situated the role of entrepreneurs in the context of policy activity involving struggles over problem framing and linking together issues competing for policy attention in non-linear and often contingent decision making processes.

But again, it was unclear exactly who were these individuals and under which conditions they, rather than some other actor, are able to help "bring the streams together" in a "policy window" where it is possible to have an issue move from the public realm onto the formal governmental agenda. ${ }^{2}$

Thus, based on a review of the MSF and metaanalysis of major applications since its conception, for example, Cairney and Jones (2015) have concluded that entrepreneurs in the context of the multiple streams framework "are best understood as wellinformed and well-connected insiders who provide the knowledge and tenacity to help couple the "streams'". Yet, they also noted that such actors cannot do more than their environments allow. They are "'surfers waiting for the big wave' not Poseidon-like masters of the seas" (Cairney \& Jones, 2015, p. 5).

Echoing these observations, several other scholars exploring the MSF empirically, and especially its application beyond agenda setting, have also pointed out the shortcomings of the notions of individual policy entrepreneurial activity found in Kingdon's work and linked it to the undifferentiated notion of a policy subsystem highlighted above (Herweg, Huß, \& ZohInhöfer, 2015; Knaggård, 2015). Entrepreneurs have been found to be organizations as well as individuals, to sometimes be heavily interlinked and at other times to be quite distinct and separate, and also, most importantly, to

\footnotetext{
2 Since the MSF was first articulated, several conceptualizations of the term "policy entrepreneurs" and their impact on policy reform or change have existed in policy studies (Cairney, 2012; Cairney \& Jones, 2015; Jordan \& Huitema, 2014; Meijerink \& Huitema, 2010; Mintrom \& Norman, 2009; Skok, 1995, to name a few) all broadly capturing the strategic opportunities that reform-minded policy actors can seize in the policy process. However, the "elbow room" available to these individuals for investing time, energy and resources towards a desired policy end is constrained by given policy and political contexts, including their interactions with other political actors and little conceptual work has attempted to move beyond early formulation and take such factors into account in their analysis.
}

take on different roles depending on their problem, policy or politics orientation.

Knaggård (2015) for example, has argued that a single notion of entrepreneurship is misplaced and rather sees the need for at least a second more loosely defined type of "problem broker" emerging out of the problem stream to popularize or highlight a specific problem frame. This kind of actor, she argues, has a primary interest in framing policy problems and having policymakers accept these frames, thereby conceptually distinguishing problem framing "as a separate process" from policy entrepreneurship and "enabling a study of actors that frame problems without making policy suggestions", unlike traditional notions of policy entrepreneurs (Knaggård, 2015, p. 1). Similarly, other scholars have found enterprising policy actors to have emerged from other streams, such as the "instrument" advocates that are strongly oriented towards devising and promoting certain policy solutions over others, regardless of the nature of the problem at hand (Voss \& Simons, 2014).

Both of these types of actors are dedicated to framing policy issues or devising alternatives and act as filters or the initial "incubators" of problems and solutions which can then be taken up at the political level where other similar, traditional, entrepreneurs exist (Zahariadis, 2007). As Ackrill, Kay and Zahariadis (2013) note, this means "no entrepreneur alone will ever be enough to cause policy reform; we always require an account of the context" or configuration of the various other actors in the subsystem. In other words, the nature of entrepreneurs and entrepreneurial activity will vary depending on the stream in which the entrepreneur is located.

\section{3. "Who Is a Stream"? Disaggregating the Policy Subsystem}

This idea of at least three distinct types of entrepreneurs suggests that a central problem in Kingdon's work with respect to agency lies in the undifferentiated notion of a policy subsystem found in his work. As the above discussion of the diverse nature of policy entrepreneurship suggests, there is a need to match agents and streams, requiring the disaggregation of a subsystem and the assignment of distinct types of agents to each stream of activities. Not only does this help clarify the nature of policy entrepreneurship, it also helps elucidate why each stream would operate "independently" outside instances of entrepreneurial activity rather than affect most policy subsystem members on a more or less constant basis. That is, the responsibility for the range of tasks to be performed in articulating policy, developing and advocating for means to achieve them and ultimately deciding upon them can be argued to fall on different distinct sets of subsystem actors; from experts in the knowledge area concerned in the first in- 
stance, to experts on policy tools in the second, to authoritative decision-makers and their colleagues in the third (Howlett et al., 2009).

Hence within the policy subsystem of actors defining a particular policy arena such as national environmental policy, for example, we can see one part of a policy community surrounding climate change issues working towards defining the nature of the problem government must address. This group exists and works independently of constituencies that develop around particular instruments (for example, those favoring emissions trading), and of coalitions of actors holding a variety of beliefs regarding factors such as the legitimate role of government in society or the degree to which public opinion will support certain definitions and courses of action which are involved in the political aspects of policy-making.

In re-visualizing streams in this way as being composed of distinct groups of policy actors within a subsystem, each different actor sub-group can be thought of as a discrete entity. This is not to say these different groups cannot share membership across the policy process, as subsystem actors engage each other to various degrees and in different forms throughout the policymaking process. But it is to say that the extent to which this interaction and overlap occurs in any particular policy process, however, is an empirical question and for analytical purposes, they can be thought of as separate bodies.

\subsection{Agents in the Problem Stream: Epistemic Communities}

In answering the question "Who is a Stream", then, while it would be possible to develop new terminology to describe each sub-group, adequate terms already exist in the policy literature which can be used for this purpose. In this light, as discussed in more detail below, "epistemic communities", a term developed in the international relations literature to describe groups of scientists involved in articulating and delimiting problem spaces in areas such as oceans policy and climate change (Gough \& Shackley, 2001; Haas, 1992; Zito, 2001) can be used as a descriptor of the first set of actors involved in problem definition.

The academic exploration of epistemic communities thus far has been dominated by examples from environmental policy, a field that is constantly involved in connecting scientific findings to policy. Haas first described the "epistemic communities" involved in deliberations in this sector as a diverse collection of policy actors including scientists, academics experts, public sector officials, and other government agents who are united by a common interest in or a shared interpretation of the science behind an environmental dilemma (Gough \& Shackley, 2001; Haas, 1992). These "epistemic communities", he found influenced "policy innovation not only through their ability to frame issues and define state interests but also through their influence on the setting of standards and the development of regulations" (Adler \& Haas, 1992, p. 378).

For Kingdon, framing or defining an issue or condition is a key activity which translates it into a problem that can be addressed by policymakers. The coupling of problem definition and policy alternative is what raises an issue onto the government agenda in the MSF. However, and as Knaggård (2015) has pointed out, analytically in Kingdon's work this coupling conflates two very distinct activities, whereby "coupling becomes the same act as defining problems" and blocks a better understanding of how policy entrepreneurs are contextually enabled or constrained in promoting certain problem definitions and not others. This is where distinguishing epistemic actors who are solely concerned with policy issues and problem framing helps to bring analytical clarity to this particular aspect of policy-making activities.

These problem-defining actors are precisely those ones identified with epistemic communities, from scientists to political partisans and others depending on the case, who are active beyond agenda setting and into policy formulation and are engaged in discourses within the problem stream which lead to the definition of broad policy issues or problems (Cross, 2015; Hajer, 1997, 2005; Howlett et al., 2009; Knaggård, 2015).

In the agenda stage, epistemic communities are crucial in leading and informing the activities of other actors, defining the main direction of the policy process followed thereafter. This path-dependent evolution of problem definition indicates, as Adler and Haas (1992) noted, that "the effects of epistemic involvement are not easily reversed. To the extent to which multiple equilibrium points are possible...epistemic communities will help identify which one is selected" (Adler \& Haas, 1992, p. 373). This, in turn, heavily influences subsequent policy deliberations and activities at later points in the policy process.

Knowledge regarding a policy problem is the "glue" that unites actors within an epistemic community, differentiating it from those actors involved in political negotiations and practices around policy goals and solutions as well as those, discussed below, who specialize in the development, design and articulation of policy tools or solutions (Biddle \& Koontz, 2014).

Several studies exist supporting this view of the perceptions of epistemic community members and the problem-framing role they play in policymaking (Lackey, 2007; Meyer, Peter, Frumhoff, Hamburg, \& de la Rosa, 2010; Nelson \& Vucetich, 2009). In his studies of global oceans research and policy, for example, Rudd $(2014,2015)$ provides important empirical findings related to scientists' framing of environmental dilemmas at the science-policy interface. In his large-n, quantitative study spanning 94 countries and meant to comprehensively cover the role of scientists in oceans policymaking, he is able to conclusively point out the 
uniformity regarding research priorities across the globe, as "once evidence is assembled and knowledge created, it must also be effectively communicated, sometimes in politicized environments, ensuring that it is effectively brought to bear on sustainability challenges. Demands on scientists to increase the level of integration and synthesis in their work, and to communicate increasingly sophisticated information to policymakers and society, will only grow" (Rudd, 2015, p. 44).

\subsection{Actors in the Policy (Solution) Stream: Instrument Constituencies}

Epistemic Communities active in the problem stream are separate but distinct from the activities of a second group of actors, "instrument constituencies", whose focus is much less on problems than on solutions. Instrument constituencies is a term used in the comparative public policy field to describe the set of actors involved in solution articulation, independently of the nature of the problem to be addressed (Voss \& Simons, 2014). Such constituencies advocate for particular tools or combinations of tools to address a range of problem areas and hence are active in the "policy" stream Kingdon identified, one that heightens in activity as policy alternatives and instruments are formulated and combined to address policy aims.

The policy instruments that are devised or revised and considered and assessed in the process of matching problems and solutions can also usefully be viewed as the cognitive constructs of specific sets of social policy actors as they grapple with policy-making. Voss and Simons (2014), for example, have highlighted the role played by those actors who, albeit originating from a multitude of backgrounds and organizations, come together in support of particular types of policy instruments; forming a second "policy" stream, the "instrument constituency". Not to be conflated with Sabatier's or Haas' notions of advocacy coalitions or epistemic communities, these actors are united by their adherence to the design and promotion of specific policy instruments as the solutions to general sets of policy problems, usually in the abstract, which are then applied to real-world conditions.

In a series of studies on how various emission trading schemes have emerged in the area of environmental policy (Mann \& Simons, 2014; Voss \& Simons, 2014), Voss and Simons have noted that, just as epistemic communities perpetuate ideas of policy problems, members of instrument constituencies are distinct and stay cohesive due to their united "fidelity" not to a problem definition or political agenda, but rather to their support of a particular policy tool or a specific combination of policy tools.

That is, the members of such constituencies are not necessarily inspired by the same definition of a policy problem or by similar beliefs, as are epistemic commu- nities and advocacy coalitions but rather come together to support specific policy solutions or instrument choices. These constituencies are thus "networks of heterogeneous actors from academia, policy consulting, public policy and administration, business, and civil society, who become entangled as they engage with the articulation, development, implementation and dissemination of a particular technical model of governance" (Voss \& Simon, 2014). These actors exist to promote and further develop a particular instrument and form conscious groupings attempting to realize their particular version of the instrument. The practices of such actors "constitute and are constituted by the instrument" and develop "a discourse of how the instrument may best be retained, developed, promoted and expanded" (Voss \& Simons, 2014). What unites these actors is the role they play in articulating "the set of stories, knowledge, practice and tools needed to keep an instrument alive both as model and implemented practice" (Voss \& Simons, 2014).

Unlike epistemic communities that pursue the translation of broad issues into distinct problems that policymakers can act upon, constituencies are more concerned with policy tools and supplying policymakers with information about the design and mechanics of these tools. Think-tanks for example fall into this category, as they provide policymakers with "basic information about the world and societies they govern, how current policies are working, possible alternatives and their likely costs and consequences" (McGann, Viden, \& Rafferty, 2014, p. 31).

\subsection{Agents in the Politics Streams: Advocacy Coalitions}

Lastly, the "politics" stream can be thought of as being the milieu where "advocacy coalitions", a term used by students of American policy-making to describe the activities of those involved in the political struggle surrounding the matching of problem definitions and policy tools (Sabatier \& Pelkey, 1987; Sabatier \& Weible, 2007; Schlager \& Blomquist, 1996) are most active. These actors compete to get their choice of problem definitions as well as solutions adopted during the policy process.

Such politically active policy actors are usually more publicly visible than the members of those groups of substantive experts who collaborate in the formation of policy alternatives and constitute an often "hidden cluster" of actors. More visible actors in the politics stream can include, for example in the case of the US Congress Kingdon examined, "the president and his high-level appointees, prominent members of the congress, the media and such elections-related actors as political parties and campaigns" (Kingdon, 2011, p. 64) while less visible actors include lobbyists, political party brokers and fixers, and other behind-the-scenes advisors and participants.

Emphasizing the important policy role played by 
these sets of political actors is central to another of the other major theories of policy-making often improperly construed as antithetical to the MSF, namely the Advocacy Coalition Framework (ACF). As is well known, the ACF was advanced during the 1980s by Paul Sabatier and Hank Jenkins-Smith as a response to perceived limitations of existing policy process research programs: the shortcomings of the stages heuristic in establishing a causal theory of the policy process, the poor discussion about the role of scientific knowledge in policymaking, the polarity of the top-down and bottom-up perspectives on policy implementation, the need to consider time horizons of a decade or more when investigating the policy process, and the need to acknowledge the bounded rationality of policy actors (see among others Sabatier, 1987, 1988, 1998; Sabatier \& JenkinsSmith, 1993, 1999; Sabatier \& Weible, 2007; Weible, Sabatier, \& McQueen, 2009; Weible et al., 2011). ${ }^{3}$

The ACF holds that subsystem actors are boundedly rational in that they employ cognitive filters that limit how they perceive information while functioning within the subsystem. Actors aggregate and coordinate their actions into coalitions based on shared policy core beliefs and several such coalitions can occupy a subsystem. Led by their primary interest in forwarding their beliefs, the realm of coalitions falls distinctly in the political vein of the policy process, as coalitions compete with opponent coalitions to transform their beliefs into policies and tend to amplify the maliciousness of those who hold opposing beliefs.

These beliefs as well as coalition membership stay consistent over time and the relative success of a coalition in furthering its policies depends on a number of factors, including external factors like natural resource endowments and the nature of policy problems that remain relatively constant over time (Sabatier, 2007). Other external factors that are also important yet more unpredictable include public opinion and technology developments. Factors that are internal include the coalition's own financial resources, level of expertise and number of supporters. Coalition members employ knowledge about what are the competing views on important policy problems or solutions in a "variety of uses from argumentation with opponents to mobilization of supporters" (Weible \& Nohrstedt, 2012, p. 127).

Although often posited by ACF advocates as comprising all actors within a policy subsystem, the role of advocacy coalitions in vying to get their preferred problem and solutions chosen in policy decisions implies that, consistent with Kingdon's ideas, they can more usefully be thought of as synonymous with activities in the politics stream (Weishaar, Amosb, \& Collin, 2015).

\footnotetext{
${ }^{3}$ Weible and Nohrstedt (2012) provide a thorough review of the theoretical evolution of the ACF since the 1980s, along with a discussion of lessons drawn from key empirical works that have shaped the framework over the last two decades.
}

\section{Analysis: Improving upon Kingdon's Work by Differentiating Subsystem Membership}

The overall argument made here, therefore, is that the three streams Kingdon described represent and are composed of the actions of three distinct communities of actors and that it is the interactions of these groups during different stages and activities of policy making, from agenda-setting to policy evaluation which drives policy-making forward, determining its tempo and content.

This is a different vision of this activity than raised by many of the authors cited above in their own efforts to develop a vision of the policy process which often conflates the activities of specific subsets of subsystem actors with the subsystem itself, or fail to differentiate, as in Kingdon's case, between the very different actors and activities involved in each "stream".

This is a useful insight in itself and brings new light to the discussion of agenda-setting dynamics Kingdon focused upon. However it is also an advance on his thinking in that it allows for a better appreciation and understanding of how roughly the same dynamics he identified as crucial at that stage of the policy making process are also crucial further down the policy process. At the stage of policy formulation, for example, the problem and policy streams can be seen to continue to share various points of correspondence during the process of articulation of policy alternatives, while the politics stream flows independently alongside these other two until it too joins the others as decisionmaking unfolds.

Figure 1 illustrates how these overall stream dynamics can be envisioned as the policy process takes place. As this figure shows, different sets of actors interact differently in different policy-related activities. The politics stream (shown as the dashed line in Figure $1)$, for example, is composed of events in which advocacy coalitions appear as key players and continues throughout all phases of policy-making, however, it does so in the background in some stages, most notably policy implementation, and often acts without entangling itself directly with the problem and policy streams during policy formulation. This set of actors and stream of events is more active during agenda setting and later during decision making through the actions of political coalitions that compete to get their interests represented and their preferred options chosen at later stages of the policy process.

The problem stream (light gray line) and the epistemic communities it involves, on the other hand, maintain a central position as most policy activity revolves around the framing or definition of an issue area. And instrument constituencies, like advocacy coalitions, wax and wane as solution-based activity occurs, being actively engaged in formulation, less so in decision-making and then again actively involved in implementation and evaluation. 
Hence, as discussed above, the politics stream separates out from the policy-problem nexus as actors interested in policy instrument formation deliberate on technical solutions to an identified problem (Craft \& Howlett, 2012). Once policy solution packages are devised, the politics thread returns to the main weave as advocates of different policy solutions compete to have their favored policy instruments selected during decision making. The activity of actors involved in the problem stream on the other hand can be seen to advance steadily throughout the policy process without bowing out in some areas as do some of its counterpart streams. And the policy stream personified by an instrument constituency remains in a tight link with the problem stream or epistemic community throughout the formulation phase-marked as it is by the matching of policy ends to policy means. The policy means or tools that constituencies are involved with can range anywhere from single tool calibrations to the instrumental logic of multi-tool mixes. The constituency need not stay united because of any other reason except for a common fidelity to a particular instrument or a particular combination of instruments. Once solutions have been proposed, the constituency takes a step back during decision making, but re-joins the policy process for implementation and evaluation.

\section{Conclusion: Implications for Further Research}

After three decades of comparative policy research that has critiqued, deliberated and debated the major frameworks of the policy process, the original assertions of these dominant metaphors often remain uncontested and with limited meaningful cross-fertilization (Sabatier \& Weible, 2014). As argued by John $(2012,2013)$ and Cairney (2013), however, the time is ripe to move the discussion of policy-making forward beyond dueling frameworks and some efforts have already been made in this direction (Howlett et al., 2015). Here this project has been extended to the multiple streams model, uniting it with several other frameworks, notably the Advocacy Coalition Framework but also works dealing with epistemic communities and instrument constituencies and their role in policy advisory systems, into a single more powerful combination.

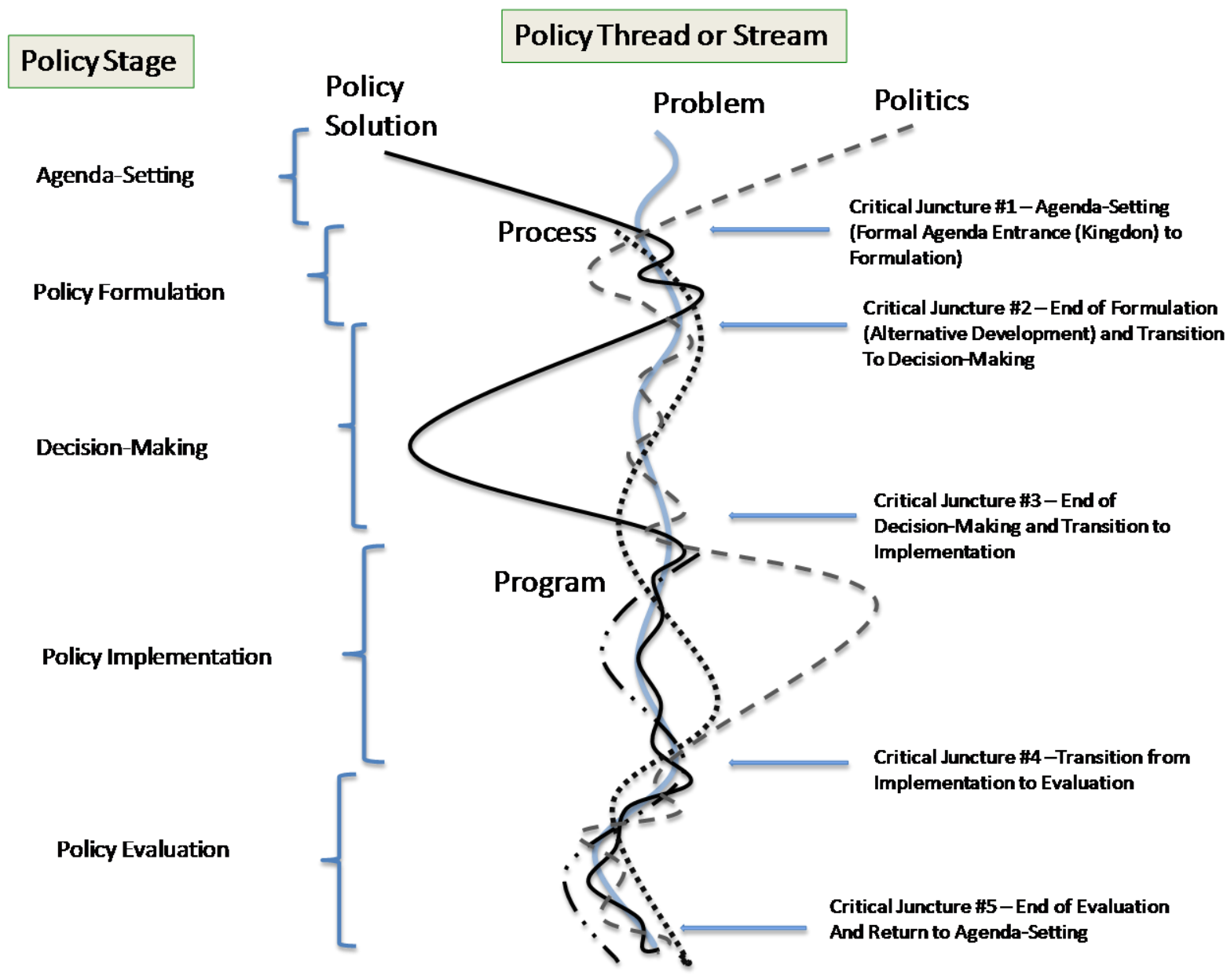

Figure 1. Five policy process “streams” (based on Howlett et al., 2015). 
The above discussion has provided an outline for a framework to operationalize Kingdon's multiple streams framework which allows it to be usefully extended well beyond agenda setting, strengthening its appeal as a general theory of the policy process.

This re-conceptualization of streams and agents, of course also begs several questions, which constitute the basis for a substantial research agenda in this area. In addition to testing the relationships set out in Figure 1 and analyzing subsystem structure empirically during various points of the policy process, a second area of further research involves answering questions regarding how to identify entrepreneurs in each stream. Similar to existing findings about brokers emerging from the epistemic communities of the problem stream (Knaggård, 2015), do certain enterprising members of instrument constituencies and advocacy coalitions become visible during formulation and subsequent phases of the policy process? How are these brokers revealed? And how do they forge connections between otherwise disjoint actor groupings in the subsystem, hence seizing opportunities to "couple" independently flowing streams? The significance of the brokerage skills of entrepreneurs has already been identified in areas such as health policy that are characterized by densely interconnected networks of policy actors, and within which successful entrepreneurs need to have the instruments to bridge connections between diverse stakeholders (Catford, 1998; Harting, Kunst, Kwan, \& Stronks, 2010; Laumann \& Knoke, 1987).

\section{Conflict of Interests}

The authors declare no conflict of interests.

\section{References}

Ackrill, R., Kay, A., \& Zahariadis, N. (2013). Ambiguity, multiple streams, and EU policy. Journal of European Public Policy, 20(6), 871-887.

Adler, E., \& Haas, P. M. (1992). Conclusion: Epistemic communities, world order, and the creation of a reflective research program. International Organization, 46, 367-390.

Arts, B., Leroy, P., \& Van Tatenhove, J. (2006). Political modernization and policy arrangements: A framework for understanding environmental policy change. Public organization review, 6(2), 93-106.

Biddle, J. C., \& Koontz, T. M. (2014). Goal specificity: A proxy measure for improvements in environmental outcomes in collaborative governance. Journal of Environmental Management, 145, 268-276.

Cairney, P. (2012). Understanding public policy. Basingstoke, UK: Palgrave

Cairney, P. (2013). Standing on the shoulders of giants: How do we combine the insights of multiple theories in public policy studies? Policy Studies Journal,
41(1), 1-21.

Cairney, P., \& Jones, M. D. (2015). Kingdon's Multiple Streams Approach: What is the empirical impact of this universal theory? Policy Studies Journal, in press.

Catford, J. (1998). Social entrepreneurs are vital for health promotion: But they need supportive environments too. Editorial. Health Promotion International, 13(2), 95-98.

Cohen, M., March, J., \& Olsen, J. (1972). A garbage can model of organizational choice. Administrative Science Quarterly, 17(1), 1-25.

Craft, J., \& Howlett, M. (2012). Policy formulation, governance shifts and policy influence: Location and content in policy advisory systems. Journal of Public Policy, 32(2), 79-98.

Cross, M. K. D. (2015). The limits of epistemic communities: EU security agencies. Politics and Governance, 3(1), 90-100.

Freeman, J. (1997). Collaborative governance in the administrative state. UCLA Law Review, 45, 1.

Gough, C., \& Shackley, S. (2001). The respectable politics of climate change: The epistemic communities and NGOs. International Affairs, 77, 329-346.

Haas, P. (1992). Introduction: Epistemic communities and international policy coordination. International Organization, 14(1), 1-36.

Hajer, M. A. (1997). The politics of environmental discourse: Ecological modernization and the policy process. Oxford, UK: Oxford University Press.

Hajer, M. A. (2005). Setting the stage: A dramaturgy of policy deliberation. Administration \& Society, 36(6), 624-647.

Harting, J., Kunst, A. E., Kwan, A., \& Stronks, K. (2010). A "health broker" role as a catalyst of change to promote health: An experiment in deprived Dutch neighbourhoods. Health Promotion International, 26(1), 65-81.

Herweg, N., Huß, C., \& Zohlnhöfer, R. (2015). Straightening the three streams: Theorising extensions of the multiple streams framework. European Journal of Political Research, 54(3), 435-449.

Hood, C. (2010). The blame game: Spin, bureaucracy and self-preservation in government. Princeton, NJ: Princeton University Press.

Howlett, M. (2012). The lessons of failure: Learning and blame avoidance in public policy-making. International Political Science Review, 33(5), 539-555.

Howlett, M., \& Cashore, B. (2009). The dependent variable problem in the study of policy change: Understanding policy change as a methodological problem. Journal of Comparative Policy Analysis: Research and Practice, 11(1), 33-46.

Howlett, M., McConnell, A., \& Perl, A. (2015). Streams and stages: Reconciling Kingdon and policy process theory. European Journal of Political Research, 54(3), 419-434. 
Howlett, M., Ramesh, M., \& Perl, A. (2009). Studying public policy: Policy cycles \& policy subsystems ( $3^{\text {rd }}$ ed.). Toronto: Oxford University Press.

John, P. (2012). Analyzing public policy. New York: Routledge.

John, P. (2013). New directions in public policy: Theories of policy change and variation reconsidered. SSRN 2286711.

Jordan, A., \& Huitema, D. (2014). Innovations in climate policy: The politics of invention, diffusion, and evaluation. Environmental Politics, 23(5), 715-734.

Kingdon, J. W. (1984). Agendas, alternatives, and public policies. Boston: Little Brown and Company.

Kingdon, J. W. (2011). Agendas, alternatives and public policies ( $2^{\text {nd }}$ ed.). Boston: Longman.

Knaggård, Å. (2015). The Multiple Streams Framework and the problem broker. European Journal of Political Research, 54(3), 450-465.

Lackey, R. T. (2007). Science, scientists, and policy advocacy. Conservation Biology, 21, 12-17.

Laumann, E. O., \& Knoke, D. (1987). The organizational state. Social choice in national policy. Wisconsin: The University of Wisconsin Press.

Mann, C., \& Simons, A. (2014). Local emergence and international developments of conservation trading systems: Innovation dynamics and related problems. Environmental Conservation, 1-10.

March, J. G., \& Olsen J. P. (1979). Ambiguity and choice in organizations. Bergen: Universitetsforlaget.

McCool, D. (1998). The subsystem family of concepts: A critique and a proposal. Political Research Quarterly, 51(2), 551-570.

McGann, J. G., Viden, A., \& Rafferty, J. (2014). How think tanks shape social development policies. Philadelphia: University of Pennsylvania Press.

Meijerink, S., \& Huitema, D. (2010). Policy entrepreneurs and change strategies: Lessons from sixteen case studies of water transitions around the globe. Ecology and Society, 15(2), 21.

Meyer, J. L., Peter, C., Frumhoff, S., Hamburg, P., \& de la Rosa, C. (2010). Above the din but in the fray: Environmental scientists as effective advocates. Frontiers in ecology and the environment, 8, 299-305.

Mintrom, M., \& Norman, P. (2009). Policy entrepreneurship and policy change. Policy Studies Journal, 37, 649-667.

Nelson, M., \& Vucetich, J. A. (2009). On advocacy by environmental scientists: What, whether, why, and how. Conservation Biology, 23, 1090-1101.

Rudd, M. (2014). A scientist's perspectives on global ocean research priorities. Frontiers in Marine Science, $1,36$.

Rudd, M. (2015). Scientists' framing of the ocean science-policy interface. Global Environmental Change, 33, 44-60.

Sabatier, P. (1987). Knowledge, policy-oriented learning, and policy change. Knowledge: Creation, Diffu- sion, Utilization, 8(4), 649-692.

Sabatier, P. (1988). An advocacy coalition framework of policy change and the role of policy-oriented learning therein. Policy Sciences, 21(2/3), 129-168.

Sabatier, P. (1991). Toward better theories of the policy process. PS: Political Science and Politics, 24(2), 144-156.

Sabatier, P., \& Jenkins-Smith, H. (1993). The advocacy coalition framework: Assessment, revisions, and implications for scholars and practitioners. In P. Sabatier \& H. Jenkins-Smith (Eds.), Policy change and learning: An advocacy coalition approach (pp. 211236). Boulder: Westview.

Sabatier, P., \& Jenkins-Smith, H. C. (1999). The advocacy coalition framework: An assessment. In P. Sabatier (Ed.), Theories of the policy process. Boulder: Westview Press.

Sabatier, P. (1998). The advocacy coalition framework: Revisions and relevance for Europe. Journal of European Public Policy, 5(1), 98-130.

Sabatier, P., \& Pelkey, N. (1987). Incorporating multiple actors and guidance instruments into models of regulatory policymaking: An advocacy coalition framework. Administration \& Society, 19(2), 236263.

Sabatier, P., \& Weible, C. M. (2007). Theories of the policy process. Boulder: Westview Press.

Schlager, E., \& Blomquist W. (1996). Emerging political theories of the policy process: Institutional rational choice, the politics of structural choice, and advocacy coalitions. Political Research Quarterly, 49, 651-672.

Skok, J. E. (1995). Policy issue networks and the public policy cycle: A structural-functional framework for public administration. Public Administration Review, 55(4), 325-332.

Teisman, G. (2000). Models for research into decisionmaking processes: On phases, streams and decision-making rounds. Public administration, 78(4), 937-956.

Voss, J. P, \& Simons, A. (2014). Instrument constituencies and the supply side of policy innovation: The social life of emissions trading. Environmental Politics, 23(5), 735-754.

Weible, C. M., Sabatier, P., \& McQueen, K. (2009). Themes and variations: Taking stock of the advocacy coalition framework. Policy Studies Journal, 37(1), 121-140.

Weible, C., Sabatier, P., Jenkins-Smith, H. C., Nohrstedt, D., Henry, A. D., \& de Leon, P. (2011). A quarter century of the advocacy coalition framework: An introduction to the special issue. Policy Studies Journal, 39(3), 349-360.

Weible, C. M., \& Nohrstedt, D. (2012). Coalitions, learning and policy change. Routledge handbook of public policy (pp. 125-137). New York: Routledge.

Weishaar, H., Amosb, A., \& Collin, J. (2015). Best of en- 
emies: Using social network analysis to explore a policy network in European smoke-free policy. Social Science \& Medicine, 133, 85-92.

Zahariadis, N. (2007). The multiple streams framework: Structure, limitations, prospects. In P. Sabatier
(Ed.), Theories of the policy process (pp. 65-92). Boulder: Westview.

Zito, A. R. (2001). Epistemic communities, collective entrepreneurship and European integration. Journal of European Public Policy, 8(4), 585-603.

\section{About the Authors}

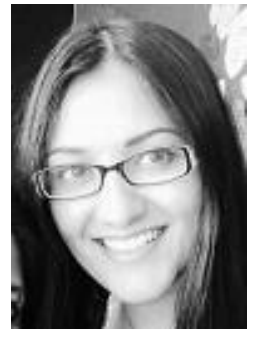

\section{Dr. Ishani Mukherjee}

Ishani Mukherjee is Postdoctoral Fellow at the LKY School of Public Policy, National University of Singapore. She received her PhD in Public Policy, with a concentration in Environmental Policy and received the World Future Foundation 2014 PhD Prize for Environmental and Sustainability Research. Her research interests combine policy design and policy formulation, with a thematic focus on environmental sustainability, renewable energy and energy efficiency, particularly in Southeast Asia. She has worked previously at the World Bank's Energy practice in Washington, DC, and obtained her BSc (honors) and MSc (honors) in Natural Resources and Environmental Economics from Cornell University.

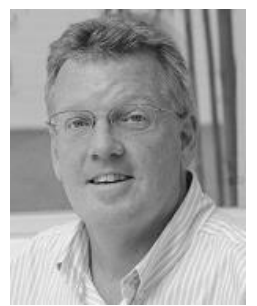

\section{Dr. Michael Howlett}

Michael Howlett is Burnaby Mountain Chair in the Department of Political Science at Simon Fraser University and Yong Pung How Chair Professor in the Lee Kuan Yew School of Public Policy at the National University of Singapore. He specializes in public policy analysis, political economy, and resource and environmental policy. His most recent books are Varieties of Governance (2015); Policy Paradigms in Theory and Practice (2015); Canadian Public Policy (2013) and The Routledge Handbook of Public Policy (2013). 